\title{
Scot Mckendick, John Lowden, Katleen Doyle, Royal Manuscripts: The Genius of Illumination
}

London: British Library, 2011

\section{Adelaide Miranda e Delmira Espada}

\section{CpenEdition}

\section{Journals}

Edição electrónica

URL: http://journals.openedition.org/medievalista/594

DOI: 10.4000/medievalista.594

ISSN: 1646-740X

\section{Editora}

Instituto de Estudos Medievais - FCSH-UNL

\section{Refêrencia eletrónica}

Adelaide Miranda e Delmira Espada, «Scot Mckendick, John Lowden, Katleen Doyle, Royal

Manuscripts: The Genius of Illumination », Medievalista [Online], 13 | 2013, posto online no dia 19

fevereiro 2014, consultado o 22 setembro 2020. URL : http://journals.openedition.org/medievalista/ 594 ; DOI : https://doi.org/10.4000/medievalista.594

Mediavalista está licenciado com uma Licença Creative Commons - Atribuição-NãoComercial 4.0 Internacional. 
Título: Recensão

MCKENDICK, Scot; LOWDEN, John; DOYLE, Katleen - Royal Manuscripts: The Genius of Illumination. London: British Library, 2011

Autor(es): Adelaide Miranda, Delmira Espada

Enquadramento Institucional: Instituto de Estudos Medievais FCSH - UNL Lisboa,

Portugal

Contacto: mmac@fcsh.unl.pt, delmiraespada@gmail.com

Fonte: Medievalista [Em linha]. №13, (Janeiro - Junho 2013). Dir. José Mattoso. Lisboa:

IEM.

Disponível em: http://www2.fcsh.unl.pt/iem/medievalista/

ISSN: $1646-740 \mathrm{X}$

\section{Recensão}

MCKENDICK, Scot; LOWDEN, John; DOYLE, Katleen - Royal

Manuscripts: The Genius of Illumination. London: British Library, 2011

Adelaide Miranda, Delmira Espada 


\section{We need to allow the books to tell their own stories ${ }^{1}$}

O estudo do fundo da chamada Old Royal Library ${ }^{2}$, integra-se numa lógica expositiva que tem vindo a ser adoptada pelas principais instituições europeias detentoras de importantes núcleos de manuscritos iluminados. ${ }^{3} \mathrm{O}$ seu programa integra uma grande exposição, a produção de um catálogo, um conjunto de aplicações electrónicas e dossiers pedagógicos ${ }^{4}$ que complementam e apoiam a mostra, assim como, um conjunto de conferências decorrentes do processo de investigação. Esta iniciativa foi apoiada por uma equipa de investigadores, que ao revisitar o fundo procurou criar novas relações entre os manuscritos, compreender a sua produção e fruição ao longo da história e a sua presença no contexto da coleção. Este projeto, uma parceria entre a British Library e o The Courtauld Institute of Art, financiado pelo Ars \& Humanities Research Council, esteve na origem das linhas definidoras da lógica intrínseca da própria exposição, dando a legítima visibilidade às investigações académicas que a suportaram.

O catálogo, cuja edição se deve ao mecenato de que se destaca a família Pigott, espelha esta mesma dinâmica. Estruturado de forma bastante clara e eficaz, apresenta duas breves introduções que contextualizam e esclarecem a metodologia do projeto. Seguemse três ensaios, resultantes dos três anos de investigação que serviram de base à preparação do evento, explorando as questões essenciais da pesquisa. O primeiro, de John Lowden (professor de História da Arte no Courtauld Institute), analisa as várias possibilidades de ligação dos manuscritos à família real inglesa, justificando a sua presença no contexto da coleção, assim como, a forma como cada um destes códices, no

${ }^{1}$ Lowden, John - “The Royal Manuscript as Idea and Object”. In Royal Manuscripts. The Genius of Illumination. Londres: British Library, 2011, p. 40.

2 Constituído por cerca de 2000 volumes, dos quais 1200 pertencem ao período medieval. A forma como estes manuscritos se agruparam numa única coleção é o tema de um dos ensaios deste catálogo.

${ }^{3}$ Miniatures flamandes, fruto da parceria entre a Bibliothèque Royale de Belgique e a Bibliothèque Nationale de France, esteve patente ao público em Bruxelas de 30.09.11 a 30.12.11 e irá agora ser apresentada em Paris de 06.03.12 a 10.06.12. A mostra de Londres decorreu de 11 de Novembro a 13 de Março de 2012.

4 http://www.bl.uk/royal. 
percurso da sua existência, se relacionou com a casa real. O segundo ensaio, de Scot McKendrick (responsável pelo departamento de História da British Library), põe em evidência, por um lado, as fortes relações históricas e geográficas que uniram, durante séculos, a Inglaterra e a Europa continental e, por outro, a herança cultural e a influência que a produção de manuscritos continentais teve no gosto da monarquia inglesa, nomeadamente através da influência do duque de Berry (irmão do Rei de Inglaterra, Henrique V) e de Eduardo IV. Kathleen Doyle (Curadora dos Manuscritos Iluminados da British Library), no terceiro ensaio, faz uma aproximação cronológica à história da Old Royal Library, refazendo a história da coleção. Por último, as 154 entradas do catálogo propriamente dito, organizadas de acordo com os seis núcleos da mostra.

The Christian Monarch, o primeiro grande núcleo da exposição, composto por 46 manuscritos datados entre os séculos VIII e XVI, põe em destaque a relação entre os membro da casa real e a igreja, testemunhando a centralidade da religião cristã na vida da corte inglesa. A sumptuosidade destes códices teve como propósito, por um lado evidenciar a riqueza e o estatuto do seu mecenas, e por outro, o desejo de glorificar Deus, eterno rei dos céus, legitimando assim o poder do monarca. Este núcleo comporta Saltérios (profusamente iluminados), Bíblias, Evangeliários, Livros de Horas, constituindo um conjunto variado de textos devocionais mais ligados à esfera do privado (por exemplo o rolo de orações de Henrique VIII - cat. 44), mas também textos devocionais de uso monástico e outros que visam a regulamentação das relações entre o poder real e a Igreja, nomeadamente registos e cartas régias (cat. 36 e 5) ou a escritura quadripartida entre Henrique VII e o abade de Westminster, John Islip (cat. 41).

O segundo, Edward IV: Founder of the Old Royal Library, centra-se especificamente na relação dos monarcas ingleses com os livros, integrando um conjunto de 16 manuscritos oriundos dos Países-Baixos, adquiridos por Eduardo IV, na segunda metade do seu reinado (1461-70 e 1471-83). Esta relação do monarca com os manuscritos flamengos, alicerçada nas fortes relações que o ligaram a esta região durante o seu exílio, forma o corpo principal da primeira biblioteca real inglesa de carácter permanente.

O terceiro núcleo, How to be a King: Works of Instruction and Advice, é composto por 25 manuscritos, entre os séculos XIII e XVI, considerados essenciais à formação dos jovens príncipes, incluindo uma cópia da primeira metade do século XIV, do famoso 
texto Secretum secretorum, do Pseudo-Aristóteles (Cat. 63). Os valores cristãos, as virtudes da conduta cavaleiresca e o conhecimento da história e dos heróis da Antiguidade formavam um conjunto de saberes indispensáveis à formação do futuro monarca. Embora sejam em muito menor número, existem também textos dedicados à educação das princesas, como é o caso do Miroir des dames (cat. 68), Miroir de l'âme, Speculum dominarum, Des Cleres et nobles femmes (cat. 70 e 71). Agregados a esta secção podemos também encontrar Bestiários (cat. 80 e 81), onde os ensinamentos dos vícios e das virtudes se revelam através das características dos animais, Bíblias historiadas (cat. 74), Vidas de Santos (cat. 78 e 79), Saltérios (cat. 82-85) e cópias iluminadas do Apocalipse (cat. 86 e 87).

O quarto núcleo, The World's Knowledge, é dedicado ao mundo do conhecimento medieval, integrando 26 volumes de temas muito abrangentes. Entre outros figuram As Etimologias de Isidoro de Sevilha, De rerum naturis de Rábano Mauro, De proprietatibus rerum de Bartholomaeus Anglicus, o Livro da Medicina de Aldobrandino de Siena, Tratados astrológicos, teológicos e políticos e um vasto conjunto de mapas.

O quinto núcleo, Royal Identity, composto por 20 volumes, selecionou obras que contribuíram para o desenvolvimento da identidade dos monarcas ingleses, legitimando, em certa medida, o seu poder. É o caso das crónicas, das genealogias, armoriais, liturgia das coroações, histórias épicas e outros textos.

O último núcleo, England and the Continent: Affinity and Appropiation, assinala a relação entre a Inglaterra e a Europa continental, apresentando uma seleção de 21 obras oriundas dos dois principais centros de produção de manuscritos iluminados: França e Países-Baixos.

Além da reprodução a cores de, pelo menos, um dos fólios, data, dimensão, cota e proveniência, o catálogo fornece ainda uma breve descrição dando uma visão global do manuscrito, que é, em nosso entender, um excelente exemplo de uma obra de divulgação ao serviço de um público alargado. Escritas de forma muito clara, numa linguagem acessível a um público menos especializado, sintetizam o essencial de cada manuscrito, deixando transparecer a existência de um estudo aprofundado do códice. 
Uma descrição codicológica detalhada, assim como um conjunto de reproduções mais alagado, pode encontrar-se no site da British Library. No final do catálogo é disponibilizada uma bibliografia geral alargada e atualizada, bem como uma bibliografia específica para cada manuscrito.

Este, é pois um dos catálogos que figurará como testemunho das exposições sobre manuscritos iluminados que ultimamente têm divulgado uma das manifestações artísticas mais criativas e originais da Idade Média, conjugando, por excelência, a arte e a história. As imagens são aqui tratadas como objecto artístico e fonte de conhecimento; um contributo fundamental na construção da História da Inglaterra, seus monarcas e respectivo contexto europeu. Optou-se, como vem sendo hábito nas grandes exposições, pelo recurso quase exclusivo a manuscritos provenientes da própria instituição. Apesar disso, não deixou de se incluir manuscritos deslocados doutras instituições inglesas, cuja presença se justificava no contexto da mostra.

Sublinha-se uma vez mais, no âmbito deste projeto, a excelência da parceria entre as várias instituições que souberam reunir esforços, ao conjugar o trabalho de investigação com a divulgação do património iluminado, numa dinâmica que visou a abrangência de diversos públicos, requalificando um período em que a criação artística foi posta ao serviço do livro. 


\section{COMO CITAR ESTE ARTIGO}

\section{Referência electrónica:}

MIRANDA Maria Adelaide; ESPADA Delmira - "MCKENDICK, Scot; LOWDEN, John; DOYLE, Katleen - Royal Manuscripts: The Genius of Illumination. London:

British Library, 2011”. Medievalista [Em linha]. N¹3, (Janeiro - Junho 2013).

[Consultado dd.mm.aaaa]. Disponível em

http://www2.fcsh.unl.pt/iem/medievalista/MEDIEVALISTA13/miranda_espada1307.html.

ISSN 1646-740X.

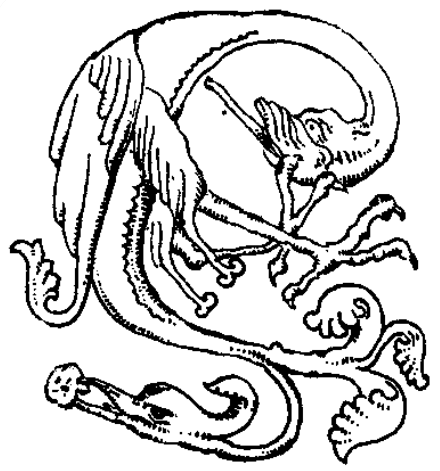

Medievalista online № 13| Janeiro - Junho 2013 ๑ IEM - Instituto de Estudos Medievais 6 www2.fcsh.unl.pt/iem/medievalista 